\title{
Understanding by the Lines We Map: Material Boundaries and the Social Interpretation of Archaeological Built Space
}

\author{
Benjamin N. Vis
}

\begin{abstract}
End users of archaeological maps are restricted in what they know about the data they are using. Mapped information is regularly used for visualisation and spatial analysis in GIS to aid interpretation. Precisely how, then, can digital spatial data best support social interpretation? Boundaries are introduced as a heuristic device to work through a series of critical observations and theoretical concepts that enable an understanding and restructuring of spatial data for social interpretation. Establishing a firm foundation for this restructuring is important to nurture a critical awareness of how archaeology can contribute to the "new territory' of GIS approaches. While this chapter focuses on the example of built environment maps-which helps to formulate pertinent questions and to demonstrate the research process - the arguments remain valid for archaeology as social science broadly conceived.

First, I will explore some limitations associated with reading built environment survey maps as an end user and reflect on conjecturing information for spatial analyses. These observations suggest that working with spatial source data demands a deep understanding of the physical information behind archaeological evidence. Second, I will introduce the notion of interpretive data as a rendition of spatial data conveying material evidence on what matters socially about physical information. This defines a human centrist remit for social interpretation which is made explicit through the concepts of material presence and agential intraactions. Third, I determine what social interpretation of the built environment entails by adopting an inhabitant's perspective and arguing the integrity of spatial analytical synchronicity in social archaeology. Finally,
\end{abstract}

B.N. Vis $(\bowtie)$

Classical and Archaeological Studies (CLAS) and Kent

Interdisciplinary Centre for Spatial Studies (KISS),

School of European Culture and Languages, University of

Kent, Canterbury, UK

e-mail: B.N.Vis@kent.ac.uk 
the chapter culminates by showing how, going forward, rigorous evidentiary understanding of spatial data grounded by an elaborate theoretical framework enables a distinct GIS approach dubbed 'interpretive GIS'.

\section{Keywords}

Archaeological evidence $\bullet$ Spatial theory and methods $\bullet$ Interpretive GIS • Built environment $\bullet$ Material boundaries

\subsection{Introduction}

In his foreword to Setting Boundaries (Pellow 1996), well-known anthropologist Edward T. Hall (1996) wrote: 'one can spend a lifetime on boundaries. That would be worthwhile work'. In fact, all of us spend a lifetime on boundaries. Boundaries as 'sites of difference' [a thought developed by Abbott (1995), Jones (2009, 2010)] are pervasive in the empirical reality of our material world. Philosophically speaking, a site of difference is not a thing in and of itself, but the edge along which a thing becomes distinct from its surroundings. As a concept, boundaries become the way in which differentiation, through observation, perception, and experience, allows us to recognise the matter and furnishing of the world. Mundane boundaries are the locations of encounter, shaping the objects and units the world consists of from various elements. Placing them within terms of Schutz's (1967) constitutive phenomenology, boundaries are the way in which we come to know the world (see Vis 2013, under review). Therefore, we all spend a lifetime on boundaries, and boundaries play a highly meaningful and determinant part in our empirical social lives.

In this chapter I endeavour to highlight and elucidate some significant ways in which boundaries can contribute to the analysis and social interpretation of spatial archaeological evidence on built environments. This is not to say that their relevance cannot be extended beyond the phenomenon of built environments, but by selecting a particular category of evidence, the value of boundaries can be more readily demonstrated. Furthermore, despite the focus on archaeological spatial evidence here, the ubiquity of boundaries in the empirical material world implies their validity as a research concept for human-environmental relations in general. Because the conceptual boundary is a spatial metaphor, it is only fitting that it is in the human manipulation and transformation of space that we should explore how boundaries can heuristically advance the use, analysis, and social interpretation of spatial archaeological evidence.

Ultimately, the aim is to provide the critical evidentiary reflection and theoretical backing necessary to convert digital spatial data, especially envisioned within Geographical Information System (GIS) software, into data that is structured by interpretive social meaning and primed to be analysed through its quantitative counterparts. Since one of the important advantages of quantitative empirical tools and information consists of the ability to generate comparative knowledge, the abstract and universally applicable notion of boundaries-conveying the empirical reality that gives our material world its shape-are well matched. The issues with creating qualitative or interpretive data for social analysis within GIS are steeped in theoretical depth concerning the nature of archaeological evidence and defining analytical purpose.

The research directions this chapter opens are found within the 'new territory' in GIS approaches that is informed by the archaeological-theoretical perspective, but not within the themes Verhagen (2018, this volume) identifies (i.e. cross-fertilisation with other techniques, network analysis, agentbased modelling, dynamical simulation modelling, or advanced statistical software). The universal significance of boundaries asserted in the opening statements sets out a path that here is developed 
from an end user perspective (i.e. analysis seeking social interpretation) on archaeological evidence on built space. Starting with the archaeological built environment survey maps which an end user may acquire, I will go through a series of observations on the way such data is presented. This brings out the complications associated with the usability of the lines on archaeological maps; moving from archaeological evidence to physical evidence, to material evidence. The theoretical implications that follow demonstrate how we can make critical use of lines on maps for spatial analysis in support of social interpretation. In conclusion, this theory is placed in the context of the requirements for developing interpretive research in a GIS environment. This has profound consequences for how we conduct archaeological GIS and how we proceed to develop new research processes with GIS. The concept of (material) boundaries is used throughout to exemplify how the staged questioning of archaeological built environment survey maps plays out. The path this sets out leads towards the theoretically and creatively enticing idea of developing 'interpretive GIS'.

\subsection{Archaeological Evidence as Lines on Maps}

\subsubsection{Boundaries in Archaeological Survey Maps}

In keeping with the geographical and landscape focus of this volume, the archaeology of built environments is taken to comprise the full scale of the relations between human constructions and the material traces of spatial transformations (i.e. developed landscapes and built-up space, such as within settlements). Except for aspects of detailed excavations, artefactual studies, and sampling of substances, archaeological information on built environment sites usually get translated into maps. The majority of such maps result from archaeological topographical surveys, employing various techniques. These may include remote sensing, geophysical and aerial surveys, and terrestrial altimetric (theodolite) surveys of the geographical distribution and shape of traces. The processed output of these is almost invariably some kind of map, showing archaeological features.

Therefore, it is in the context of the archaeological survey map that we first consider the pervasiveness of boundaries as sites of difference shaping the objects and units the world consists of. This thought has been developed in the social sciences (see Abbott 1995; Jones 2009, 2010) but can be brought to bear on the world of material objects too (Smith and Varzi 1997, 2000; Smith 2001; see also Vis 2014a). Smith and Varzi's (1997, 2000) bona fide boundary concept holds that entities emerge from the spatial discontinuities or physical heterogeneity along their edges. It follows that boundaries themselves do not exist as things. Rather they convey the location where physical distinctions take place. The opposite of bona fide boundaries is fiat boundaries, which Smith and Varzi define as all distinctions that are not associated with spatial discontinuity or physical heterogeneity for differentiation. In other words, fiat boundaries are based on ideas and conventions, and this explicitly includes maps. In archaeology, our maps are based on physical traces which we then seek to interpret.

So, if we follow Abbott (1995: 857), in that '[...] we should start with boundaries and investigate how people create entities by linking those boundaries into units. We should not look for boundaries of things but things of boundaries', we are caught in a process of twisting conversions (see Vis 2014a). By working from a mapped representation of a physical situation (a built environment), we must first work through the symbology that conveys the morphology of traces to determine the physical entities they are traces of. After we have determined the physical entities, their edges, or outlines, become our starting point for bona fide boundaries. In turn, we look through a theoretical and interpretive lens to define how we understand these sites of difference (fiat) while we continue to look empirically to acknowledge the material properties that articulate the qualities of the distinction (bona fide). There is no limit to the scale of bona fide boundaries, and therefore we could go down to the level of particle physics. For the sake of pragmatism as commensurate to our field of 
research, we should declare our scale of operations as that of human beings building space. The resolution of detail in information can then usefully be set at the level of discrete humanly occupiable spaces (see Vis, under review). Hence, our boundary perspective on archaeological built environment survey maps heuristically focuses on identifying the way spaces are separated to form distinctly circumscribed spatial subdivisions.

\subsubsection{Reading Lines on Maps}

For argument's sake, we could say that the primary source of information on archaeological topographical survey maps consists of lines. More elaborate use of symbology may exist to distinguish kinds of lines, but predominantly the occurrence and shape of archaeological traces of spatial transformations are visually represented by lines. Thus, the end user or interpretive analyst would likely encounter archaeological evidence of built space as lines on maps when acquiring spatial data. This confronts us with a twofold heuristic challenge: First, how much do we actually know about the empirical (physical) reality these lines convey as archaeological evidence? Second, how do we get to the entities shaped by linked-up boundaries on the human scale of occupiable spatial subdivisions? This will highlight limitations to the usability of information contained in archaeological spatial data which are not necessarily new, but are seldomly made explicit.

The first consideration regards the physical characteristics and condition behind the classification that is implied by any line mapped as archaeological evidence. We can commonsensically acknowledge the heterogeneity of any construction in both the technique and materials used (e.g. bricks and mortar). Even cyclopean masonry (e.g. Mycenaean and Inca architecture) does not render a constant surface. Yet, a line suggests that the physical characteristics along its course remain the same. Especially when architecture is concerned, it invokes the impression of the regular and constant vertical faces of modern construction we are used to, obscuring any specification of the physical characteristics that may afford human beings a different relationship with that spatial distinction. Lines also suggest a parity of physical conditions that applies along all full lengths. The same visual style of line can be used from archaeological feature to archaeological feature, whereas we know that preservation is rarely equal throughout a site. Beyond environmental forces and historical events acting on spatial constructions, the original characteristics of building and engineering may have influenced how spatial constructions appear as an archaeological trace. On top of this ambiguity, which is by and large intrinsic to archaeological evidence, very often the same style line can be used for multiple conditions and situations within a single plan.

Two of the most common additions to enrich a single-line style are dotted (or rhythmic) lines and (irregularly) intermittent lines. Dotted lines are intuitively used and understood as archaeological features mapped with a degree of uncertainty (cf. Hutson 2012). More often than not, it is still unknown or unqualified what this uncertainty consists of or even whether the dotted line is a projection of an educated guess or an expectation. It is useful to alert us to uncertainty, but such lines are still not straightforward to work with since it can be doubted what kind of physical condition they convey. Intermittent lines are different. Often we see bits of lines of irregular length, which in most cases suggest actually separate traces. The immediate difficulty with this is that it is, physically speaking, entirely unclear to what extent the physical condition suggests that some of such traces belong to the same spatial subdivision. This applies when we first already assume that all traces are of the same physical construction. Intermittent lines create the physical suggestion of poorer preservation than elsewhere on a site where longer continuous lines are used. However, there is also the option that visual intermittency is entirely justified by intentional physical construction (e.g. gaps for passage).

The practice of mapping is wrought with written and unwritten conventions. Beyond sustained critiques of mapping in geography in general 
(e.g. Monmonier 1996; Wood 1992; MacEachren 2004; Lilley 2011), Hutson (2012) offers a particularly thorough review of the conventions used in archaeological mapping of Maya architecture. It shows the potential traps of reading Maya archaeological site maps without preparation, relying on experience with other maps. The particular practice of 'prism mapping' of architectural volumes is deceptive and not even consistently applied within Maya archaeology (if the application is documented at all by the mapper). The outer lines of features often, but not always, provide the outlines of the trace, and the diagonals, often, but not always, represent simply the height of the mounds of rubble (resulting from building deterioration and collapse).

Other archaeological conventions that map the same traces (but not the same physical information) include hachures, contour lines, and outlines. Hutson (2012) demonstrates hachures provide more information about length and steepness of the slope of mounds of rubble than do prisms, while contours and outlines could arguably be seen as more objective. However, he refuses to argue in favour of any one approach. Instead, Hutson follows Galison (1998, 2000, 2010) to point out there is a difference between mechanical objectivity (removing one's interpretation from representation and automation) and judgmental objectivity (allowing one to add clarity from experience and interpretation) in maps. ${ }^{1}$ Since all representation is interpretive, we can refer back to the fiat nature of maps (Smith and Varzi 1997, 2000). It remains unaltered that all these conventions of representation can use a similar visual style of line, which the end user must make sense of as

\footnotetext{
${ }^{1}$ Galison $(2000,2010)$ discusses the historical progress from 'genial depiction' before 1820, 'mechanical objectivity' between 1820 and 1920, to 'judgmental objectivity' after 1920 in scientific or knowledge-based images. The latter two intermingle, as they do in Hutson's (2012) view. In the end, all maps and mapped representations are also images (Aitken and Craine 2006) and can be evaluated in this same context, which is usefully paralleled by understanding the historical development of cartography [see Lilley (2011)].
}

physical information. However, historical examples in Hutson (2012) may remind us of alternatives to using simple lines. This may evoke impressions of 19th century urban surveys, which sometimes added symbols to lines in order to express spatial relations (see Oliver 1993). Not all walls are built the same. There is an array of ways in which walls connect inside to outside and determine degrees of spatial separation. When examining assortments of buildings, a typical example revolves around whether or not a building consists of multiple rooms. Seemingly internal arrangements could in fact be physically enforced separations, therefore composing an accretion of buildings, accessed separately. ${ }^{2}$

\subsubsection{Documenting the Physical Information that Matters}

Depending on scale, survey technique, and resolution, simplification and visual classification of lines on archaeological survey maps are completely understandable and indeed unavoidable (cf. Hutson 2012). An end user will likely not question the line(s) mapped as designated part (s) of any particular archaeological feature, assuming parity of physical information for the shape. Yet, the difference in material conditions and situations either from line to line or along a single line may provide valuable clues for the spatial structure they create. When the ultimate aim is analysing built space for social interpretation, all of this truly matters. At the same time, we can normally safely assume that information is never meaningfully obscured. In fact, the integrity

\footnotetext{
${ }^{2}$ It can be admitted that even in state-of-the-art maps of the contemporary world, such as Ordnance Survey MasterMap in the UK, several polygons can be used for a single building. There is no information to know when polygonal separation implies an internal or external spatial arrangement. Naturally the purpose of each map differs. Embracing the material nature of archaeology, meticulous physical information would be justified.
} 
of lines on a map is such that it could correctly convey the inability of the mapper to distinguish or interpret the physical situation further.

What the situation calls for is at least the equal care for making metadata available. Unfortunately, the archaeological fieldwork reports that may be able to shed some light on the physical conditions and preservation throughout a site, the environmental and visibility conditions during the work, or the conventions and pragmatic decisions made, are not always easily accessible or even available. Even if this information is available in written form and personal communication, then still it is unlikely to specify and comment on each archaeological trace that it mapped. Moreover, it is to be expected that future analytical purpose may generate questions that could not be foreseen or considered when the maps were produced. This means that even the most carefully presented and documented spatial data may ultimately result in unexpected ambiguities. Therefore, however unfortunate it may seem, after due scientific diligence, the remaining ambiguities can only be solved by consistent yet pragmatically informed rules of thumb.

This realisation must not be seen as an excuse not to produce the best possible metadata and data (re)presentation. Nor will this realisation change the fact that each specific archaeological project may allow for more information being recorded or the same information being recorded in a more useful way. Most significantly, if the archaeological survey map is the end product of a project, it would be fair to expect that it is being prepared in a best possible way to enable flexible future potential use. With the wealth of mapping conventions and symbologies available, especially in this digital age, we have far from exhausted the possibilities to improve on how physical information is conveyed on our maps. ${ }^{3}$

\footnotetext{
${ }^{3}$ It may be worth mentioning here that with new recording technologies, especially high-resolution 3D photogrammetry and laser scanning or LiDAR, a cleanly presented 2D archaeological map as end product could systematically refer back to the much fuller source of information of the original digital records. Kyriakidis E (2016, personal communication) argued the advantages of a similar
}

Where the onsite conditions allow, spatial-material information such as internal arrangements, separate yet associated traces, changes in preservation within the same feature, relief characteristics, etc. could be conveyed with the lines we map.

\subsubsection{Complementing Lines that Stop}

Until now we have been using the term archaeological traces to characterise archaeological evidence, whereas it was proposed that at the human scale information on built environments should distinguish discrete occupiable spaces. Lucas (2015) cautions against the dominant view of archaeological evidence as fragments. However, it is fair to say that there is an important discrepancy in terms of completeness between traces of a built environment and spaces of a built environment. We know that due to site formation processes, there is no perfect preservation of past situations. Yet, social interpretations in archaeology are usually concerned with understanding situations that occurred in the past. By stating 'finding remnants of an assemblage is not the same as finding an assemblage itself', Lucas (2015: 321) urges us to reflect on what survives: archaeological evidence seen as relics. In the context of going from traces to spaces, metaphorically a past lost to a past found, the resolve lies in redressing fragments as surviving traces of entities from a past situation. ${ }^{4}$ Following the

workflow for digitally producing the $2 \mathrm{D}$ map of ancient Eleusis from $3 \mathrm{D}$ information. If we can ensure data lineages through stable links and unique identifiers, this may prove a significant advantage in the future. Providing a data lineage still does not exonerate us from a responsibility to produce our mapped interpretations with the most complete and usable information in flexible and readable formats.

${ }^{4}$ It should be acknowledged that this is not an argument against the truism that interpretations of the past are a product of the present. However, it is asserted here that a different kind of knowledge is produced from a strict adherence to Lucas' (2015) alternative of seeing material evidence as relics (evidence of why things survive), which suggests a focus on the formation, meaning, and relevance of archaeological traces as entities in and of themselves. 
understanding of boundaries posited earlier, entities as they occur to us should be understood by the boundaries from which they emerge. Since through site formation we tend to lose the occupiable spatial entities of the past, we must first ensure our spatial data conveys the bounded spaces of the built environment. This will require a process of, first, interpreting well-preserved traces into spatial subdivisions, then, applying critical conjectures and expert judgments on the basis of the physical information that archaeological survey maps contain.

This brings us to a further significant ambiguity about the lines we map, which is the typically impossible to answer question: why does a line stop? We have briefly touched upon the reasons for the intermittency of lines, but it is worth giving interrupted lines more explicit consideration. If distinguishing the spaces of a past built environment depends on conjecture due to the fragmentary nature of persistent traces, linking up and filling in the gaps is most reliably done by knowing why a line representing a physical trace stops. All we know when a line stops is that the feature must no longer be perceptible or measurable. Beyond that obvious reply, there are several reasons why this may be. The specific reason can impart physical information that would aid one to make reliable conjectures of spatial information. But first we should attempt to discern if it is a simple onsite, technical, or archaeological visibility problem. This could include problems with vegetation or the limited exposure of archaeological traces on the surface, limitations to the equipment used, e.g. obstruction or environmental physics (e.g. blockages and distortions of geophysical signals), or did the archaeology literally recede into the ground? Beyond compromised visibility, we must assume the physical trace did actually stop.

Both in the field and especially once recorded and mapped, it is not unusual that one can no longer distinguish why a feature or line representation appears truncated (e.g. Demarest 1997). I will list a few fairly straightforward reasons. First, what appears to be a truncation is not necessarily truncated. The features could be intentionally constructed, i.e. actually preserved and originally finished that way. This is arguably the most important distinction: do we see the representation of the finished article thanks to decent preservation or is the shape of this feature a representation of something broken? If the latter, there are still many options. Was the feature destroyed and, if so, when, by whom, and how? Did it deteriorate over time and, if so, by gradual dilapidation of the original feature after disuse or due to other site formation processes? Was it damaged by modification, reuse, or reappropriation in the ancient or recent past? Did it suffer from decay of perishable building materials or decay due to the perishing of originally incorporated natural elements (such as trees and plants)? Was (part of) the feature removed by either animals or humans after disuse or abandonment? Without a symbology for line ends, when conditions of archaeological recording allow for it, the end user will once again rely on rules of thumb to carry out the conjectures. Fortunately this can be done in critical and archaeologically knowledgeable and sensible ways (see Vis, under review, 2014b). Once the metadata of the project as well as spatial data and analogous information from historic and cultural proximity have been exhausted, one can still apply visual and morphological contrast when constructing complementary data, document the applied rules of thumb, and mark up data for easy separation of these conjectures from retentions of originally acquired spatial data.

\subsubsection{Conjecturing Entities}

While conjecturing is not as strong a process as fully fledged reconstruction, there is a risk of getting caught in the fallacy of perfection. In archaeological reconstruction, there is the tendency of reconstructing everything to an absolutely pristine and clean state. Buildings and surfaces are all fully functional and, in outstanding condition, their environments devoid of any 
form of pollution. One could argue this striving for perfection is a kind of hyperrealism. The reconstructed situation is not one that likely ever existed. A true reconstruction of the past should account for areas laying fallow and buildings in disuse or disrepair. Such occurrences would have been part and parcel of a built environment in flux. Beyond the visual impression, the critical social interpretive importance of perfection generated by conjecture or reconstruction can vary. This depends on the purpose of analysis or interpretation, i.e. what is the newly constructed data supposed to comment on or contribute to?

To illustrate this, let me err on the spatial side of the analytical spectrum. The reliability of population estimates based on buildings heavily depends on knowledge or assumptions that determine which were occupied and which had only occasional, shared, intermittent, or partial use (introducing degrees of spatial duplication or redundancy). However, a general understanding of the functional structure or spatial experience and opportunities for inhabitants does not rely on information about which house was occupied at each specific moment in time or its state of repair. From our own experience, we can accept that when a house is unoccupied, would we always know? And when it is dilapidated, it is still recognisable as a house and still poses a physical impediment to access that space. The building still has potential to be a household or to be repurposed. The space and the experience of that space is still structured in roughly the same way, even if the affective and sociocultural context may differ from particular case to particular case. The point is to alert us to the fact that when the notion of occupiable space (to understand how boundaries compose built environments) requires us to conjecture, we create an approximation of a situation in the past, not a reconstruction of any particular situation in the past. A sufficiently critical research design will be aware of both the social interpretive limitations and opportunities this offers.

Crucially, working on archaeological maps of built environment sites from the perspective of boundaries, requires us to ask pertinent questions that improve our understanding of the physical information that first generates and subsequently is represented by our spatial data. Understanding exactly how physical information is captured in spatial data helps us to (re)interpret the format and representations that spatial data is presented in. Furthermore, critically (re)assessing spatial data representation makes us reflect on which physical information exactly supports our understanding of how spatial relations and morphology are determined. Going through this process means that when we move on to spatial analysis and social interpretation of built space, we are much better prepared for data treatment. The rigorous questioning and processing of archaeological evidence up to this point also provides nonprescriptive advice for those looking to improve the way archaeological built environment maps are drafted and published with a view to future analysis. Now that our lines on maps are essentially converted into the bona fide boundaries of a past situation, we can only commend the creation of a precisely defined archive of physical information. The next step towards spatial analysis for social interpretation requires that we are equally critical of the theoretical assumptions such social interpretation is based on.

\subsection{The Material Nature of Boundaries}

\subsubsection{Interpretive Data}

Having arrived at this stage, we are able to examine archaeological built environment maps for the physical information they contain and identify the boundaries shaping the entities of which the built environment consists. We must now move from bona fide physical presence of boundaries to fiat, to address how we understand their presence interpretively. Analysing physical presence results in little more than dimensions: information about the geometry, topology, morphology, and topography of built space. The difficulty with such information is that it is entirely contingent whether it has any bearing on social 
understanding. ${ }^{5}$ The evidence base of archaeology is distinctly material, which is arguably why the discipline has struggled to contribute more substantially to social theory and synthesis has traditionally shown little attention to material integration (Sherratt 1993; Vis 2009). What this foregrounds is that our precise understanding of empirically derived (mechanical objectivity) archaeological evidence as physical evidence (judgmental objectivity) (cf. Galison 1998, $2000,2010)$ has yet to transition into material evidence.

This deliberate distinction of material evidence is meant to alert to us that data which captures material evidence must directly be of an interpretive nature. The next step towards social interpretation of built space is thus to construct interpretive data. Interpretive data redirects traditional data interpretation with precision and rigour, because it structurally links the empirical origins of spatial data to the ideas we have about them. These structural links provide the bridges that resolve the leaps between ontological registers (cf. Lucas 2015) that trouble and restrict the value of many archaeological interpretations. Rigorous use of interpretive data also carefully delimits the ontological register of interpretation, i.e. it ensures that data is commensurate with the understanding sought through analysis.

Crucially, then, recognising the interpretive nature of material evidence and the subsequent construction and use of interpretive data would contribute to more rigorous theory building and causal explanation in archaeology. Structuring evidence accordingly provides concepts to work to in the middle range of 'empirical theory' and consequently to construct better arguments on the basis of analysing this evidence (sensu Smith 2011, 2015; Ellen 2010). Nicholas and Markey (2015: 287) formulate the questions well: 'how do we know what we know about

\footnotetext{
${ }^{5}$ Even the most abstract, and deemed objective, way of measuring is typically based on units recognised and conceptualised by humans (e.g. metres). Purely dimensional analysis expressed in such units may have value for the hypothesis that such units were used in the construction of the built environment.
}

the archaeological record; and what types of evidence suffice for providing adequate "proof" for our interpretations?' Understanding archaeological evidence as physical evidence on the one hand and material evidence on the other provides the basis for establishing categories that enable arguments on a particular plane of interpretation.

\subsubsection{Material Boundaries}

How do we make our boundaries of physical information on the built environment into material boundaries? This requires a careful definition of their material nature. Positing a cogent and useful critique of archaeological theory and argumentation, Wallace (2011) proposes and defines the notion of the material. Critical realism offers a philosophical ontology to facilitate the development of epistemology in substantive disciplines (formed by a substantive domain) (Yeung 1997; Sayer 2013; Cox 2013). Wallace's intervention is aimed at the postmodern (or possibly post-postmodern) tribulations in archaeology that at best seem to find compromise in relativist acceptance leading to (often uncritical) eclecticism in theory and methods (see Fahlander 2012; Bintliff and Pearce 2011; Vis 2012).

Even more compelling than its critiques are critical realism's concepts and processes which link empirical and conceptual modes of research (or quantitative and qualitative social science, see Pratt 1995). Therefore, critical realism is hypothetically a particularly suitable match for the discipline of archaeology (see Wallace 2011; Vis, under review for elaborations). The critical realist focus on forming ontological entities and the categories it contains based on causality-in terms of specific causal powers emergent from internal relations-is what allows the material to gain a particular meaning. The physical and environmental processes operating in the matter of the built environment exist without human engagement with the built environment. The material, then, is what emerges when sociocultural and physical aspects become necessarily internally related through human interaction in 
time-space (Vis, under review; adapted from Wallace's (2011) original reasoning). Consequently, material boundaries refer to the understanding of the causal powers emerging from human interactions constructing or encountering the physical edges of occupiable spaces in the built environment.

\subsubsection{Material Presence}

A thorough understanding of material evidence is needed to characterise the kind of understanding a category of the material (here: material boundaries) might permit us, in this case limited to a spatial lens on built environments. This section presents a theoretical context to knowing what the material nature of our evidence is evidence of, or, what I mean by social interpretation.

It is important to recognise that material evidence is still a category of empirical information and therefore adheres to an empirical tradition of knowledge production (cf. supporting Smith's (2015) 'better arguments'). The usual mode of conduct that sees archaeology interpret data, even if we can identify various archaeological data as unwittingly interpretive data, ${ }^{6}$ has relied heavily on correlating analogous information. Citing ethnographic, (ethno)historical, and experimental sources of information (used as analogous verification for interpretations), Nicholas and Markey (2015) develop an argument for the use of 'traditional' or 'indigenous' knowledge in archaeology. Questions can certainly be asked about to what extent treating evidence empirically is the only valid structure of reasoning. A critical realist would not deny indigenous knowledge causal power. In explanation (why something happened or occurred in that way), indigenous knowledge will play an equally valid role alongside history, personal agencies and

\footnotetext{
${ }^{6}$ For example, the notion of a house or residential building appearing as a unit on a map constitutes a type of interpretive data. It conflates conceptual understanding with physical characteristics. Unfortunately, such conflation is often used as a layman's term, therefore precluding knowledge on how the unit of analysis causally relates to the interpretation.
}

memories, sociocultural systems and categories, and human-environmental relationships, both internal and external to the situation or phenomenon being studied. What such knowledges demand is a structural linkage of that understanding to archaeological evidence. In this chapter, archaeological evidence has become material evidence, and all we know about this evidence is that it refers to a presence to human beings situated in the past. Therefore, the empirical information we are restricted to is material presence (see Vis, under review, 2016).

The interpretive perspective of material presence, however, seeks not to explain exactly and comprehensively why a social empirical reality occurred. Despite this limitation, the social significance of material presence (a dynamically and generatively affective and afforded causal power) will have developmental resonance. Explaining occurrence would be tantamount to knowing exactly all causal powers working towards production in some detail. ${ }^{7}$ Instead, when presence is material we are restricted by the resolution of information invested in the social, physical, and temporal processes becoming internally related to form the material (cf. Wallace 2011). Interpretive knowledge creation will result from and is delimited by the definition of that entity and the causal powers of the specific category of it that forms our field of interest (here: material boundaries of the built environment). This is not to say that when studying material presence constitutive or supplementary causal powers have disappeared, but they have become indistinct registers of understanding. Therefore, they are simply not the purview of research operating from that perspective.

In contrast, in this chapter, the further restriction to spatially determinant characteristics is the pragmatic effect of the pervasiveness of

\footnotetext{
${ }^{7}$ For example, regular flooding in combination with a dependence on a periodically flooding water source may cause a community to build on poles. Flooding is a strongly determinant part of explaining the occurrence of building on poles. Yet, regardless of why raising buildings onto poles may have been necessary, this way of building will have social (affective and afforded behavioural and developmental) effects.
} 
generating spatial information in past and current archaeological practice. Allowing the spatial characteristics of material evidence to speak without analogies or verification derived from other kinds of evidence may feel unnecessarily restrictive $^{8}$ to some. To me it is a fair and necessary challenge when we consider that for much of human development we do not have other types of (social) evidence available. ${ }^{9}$

\subsubsection{Material Boundaries as Agential Intra-actions}

I will concede that archaeological and geographical theorising - especially as it is progressing from discursive systems theory and agency to ANT (Actor-Network Theory) and its influence on materiality - is producing ideas that resemble critical realist emergence. Critical realism is meaningfully introduced as a frame of reference for structuring the conceptual development of our social interpretive endeavour. Wallace (2011) is right to recognise that archaeology can inject material cogency into critical realism, which in turn helps to overcome the contradictions and fallacies stemming from the disciplinary split between scientific empiricism and social interpretation (Vis, under review). The

\footnotetext{
${ }^{8}$ Interpretation from this perspective-i.e. not seeking direct comparison from other casuistic evidence to draw analogies with the material evidence encountered-is necessarily subjective and self-referential. Such interpretation is in constant reference to how we understand and experience our relationship with empirical reality. Rather than drawing on any particular case, this perspective includes all the knowledge and experience researchers have acquired about humanness in their own lives, structured by theoretical constructions and concepts derived from rational reasoning. This is where we must acknowledge again that how we have been brought up and taught to think matters to evaluating the validity of reasoning. To avoid the suggestion of a false categorical opposition, note that Nicholas and Markey (2015: 290) indicate that indigenous knowledge, likewise, both results from 'learned experiences and explanations' and is characterised by empirical observation, repetition, verification, and inference.

${ }^{9}$ Working exclusively with spatially relevant evidence should not be confused with the 'spatial fetish' of spatial science [see Werlen (2005), Zierhofer (2002)].
}

flexibility of the philosophical structure and processes this provides, as well as the clarity of language in social scientific adaptations, I find are far preferable to the imprecisions and metaphysical truisms ANT-inspired theory produces. Like Smith (2015), I argue for interpretation based on causal explanations and mechanisms. To this end, the understanding that was needed to construct and structure empirical information as interpretive data permits the researcher to organise, query, and rearrange data in an exploratory way, leading to new understanding and interpretation (see below). For this iterative research process, critical realism is more appropriately matched.

Against this backdrop I will introduce another concept that recently has been gaining traction in the social sciences (Kleinman 2012) and is now finding its way into archaeology, called agential realism. Albeit complex and highly abstract, the agential realist view on empirical evidence can add detail to the notion of the material as an emergent entity, thanks to emphasising its performative dimension. In agential realism, things or phenomena emerging from discursive humannonhuman interactions are called agential intraactions (Barad 2003). Meirion Jones (2015) argues to redress the archaeological perspective on material evidence in agential realism to move away from an inert object-like world and to re-emphasise interaction and constitution. This is sensitive both to the archaeological appreciation of the mutability of material and in the social interpretive sense to regarding the world as being alive and changing. In order to nurture an understanding of seeing phenomenal emergence through discursive interaction (the phenomenon central to this chapter is the built environment composed of boundaries), I quote Barad's (2003: 815) definition in full, before I will make connections to ideas originating from more familiar discourse:

[...] phenomena are the ontological inseparability of agentially intra-acting "components." That is, phenomena are ontologically primitive relationsrelations without pre-existing relata. The notion of intra-action (in contrast to the usual "interaction," which presumes the prior existence of independent entities/relata) represents a profound conceptual shift. It is through specific agential intra-actions 
that the boundaries and properties of the "components" of phenomena become determinate and that particular embodied concepts become meaningful. A specific intra-action (involving a specific material configuration of the "apparatus of observation") enacts an agential cut (in contrast to the Cartesian cut-an inherent distinction-between subject and object) effecting a separation between "subject" and "object." That is, the agential cut enacts a local resolution within the phenomenon of the inherent ontological indeterminacy. In other words, relata do not pre-exist relations; rather, relata-within-phenomena emerge through specific intra-actions. Crucially then, intra-actions enact agential separability-the local condition of exteriority-within-phenomena. The notion of agential separability is of fundamental importance, for in the absence of a classical ontological condition of exteriority between observer and observed it provides the condition for the possibility of objectivity. Moreover, the agential cut enacts a local causal structure among "components" of a phenomenon in the marking of the "measuring agencies" ("effect") by the "measured object" ("cause"). Hence, the notion of intra-actions constitutes a reworking of the traditional notion of causality.

At the risk of exposing my inferior understanding of discipline-specific intricacies at play, to me, there is significant resemblance to the way interrelated causal powers in critical realism drive emergence. This logic provides the basis for phenomena and all associated entities (objects and categories) but also defines the substantive domain of research (cf. Sayer 1993; Yeung 1997; Pratt 1995). The idea of separability and exteriority resembles the logical destination of going through the implications of autopoiesis in systems theory. When systems are enacted, their self-generative inherent coherence contains their own distinctions towards their outside (Luhmann 1986; Arnoldi 2001). In the context of built environments, especially the incorporation of the material dimension of architectural systems into social scientific constructs is relevant as such incorporation permits the bounding of space (Koch 2005; Vis 2009).

Furthermore, the agential cut seems to represent the ability to separate oneself as an agent or researcher from the phenomenon one studies and thus co-constitutes. By the same token, it enables a distinction between human agency and nonhuman agency, even if all such 'bodies' partake in the constitutive material-discursive practices of materialisation (see Barad 2003). This connects well to agency as causal power, which is suggested in Wallace's (2011) proposition that material has 'agency without intent' which follows on from Fletcher's (2004) 'actors without intent'. The realm of phenomena may naturally include things in which humans do not partake. Consequentially, I agree with Meirion Jones (2015) that nonhuman agency should not be reduced to human agency. Distinguishing types of agency is an important corrective on the ANT-inspired idea that humans and nonhumans must possess equal agency (as in symmetrical archaeology). The logical extreme of the latter is that nothing can be distinguished discretely (represented by terms such as mixtures and meshworks) (Webmoor 2007; Webmoor and Witmore 2008; Ingold 2008; for critique: Wallace 2011; Vis, under review).

\subsubsection{Human Centrism in Interpretive Research}

Declaring for purposes here that my aim is to equip analysis seeking social interpretation, the salient differences with a mixtures and meshworks view arise from the start. Critical realist logic serves the interests of human understanding. It holds that if something has effect (i.e. the exercise of causal power), it must exist. Taking the vantage of everyday human experience, it is virtually impossible to deny the existence of discrete objects and categories, even if through alternative lenses (e.g. scientific magnification) everything may end up as mixtures of small particles. The human frame of reference matters to acknowledge which part of reality (the field of interest) we are trying to understand. Therefore, exactly why there is a need to be guarded in explaining that scientific proceedings are different when we as human beings study human beings, I have yet to grasp (insofar as we accept that the nature of human beings is captured in the category of our species). 
Especially when conducting interpretive scholarship rather than ethology, everyday human experiential knowledge ${ }^{10}$ is an appropriate frame of reference, which applies to all members of our species.

It seems an irrefutable truth that if the notion of species bears any relevance, a different dimension to understanding is available when we are concerned with our own, and we can operationalise this in research. Seen from Barad's agential realism, the specificity of the agential intra-actions of research on human beings by human beings would suggest the same. The consequence is that we can understand phenomena involving human agency (not necessarily human agency exclusively) differently from phenomena not involving human agency. A monist philosophical stance, therefore, does not require perspectives informed by totalising mixtures and symmetry (sensu Webmoor 2007; Webmoor and Witmore 2008; cf. Hodder 2014). Human centrism can be a permissible mode of knowledge production even if metaphysically we can agree that human beings are not situated centre stage by default. So '[...] we do not have to assume that materials can only be understood because of their mediation by human cultural or social activities' (Meirion Jones 2015: 334).

Agential realism supports the analysis of assemblages with an active role for the material. The associated agential distinctions support a mode of understanding that is particular to when assemblages including humans are concerned. If we try to describe this 'humancentric' stance in Hodder's (2014) asymmetrical relations between humans and things, we get something like this. The situation where things depend on things (TT) is not considered separate from relations that involve things depending on

\footnotetext{
${ }^{10}$ Critical realism evaluates knowledge in terms of 'practical adequacy'. Knowledge that is useful in and applicable to empirical situations is better than knowledge that is not. Knowledge and its concepts need to be revised when empirical situations are encountered to which it cannot be applied. This is the principle of iterative abstraction (Sayer 1981; Yeung 1997).
}

humans (TH) or humans depending on TT or when things depend on things that depend on humans. Or, in critical realist terms: for the causal power of social science (or social interpretation) to occur, the participatory presence of human beings and their influence are necessary. On the basis of Bohr's physical experiments, Barad's (2003) arguments suggest that since the conjunction of machine and object of study creates a particular situation, this intra-action (of machine, object, researcher, environment) 'causes' an outcome to emerge that otherwise would not have existed. This reworking of the notion of causality again roughly pertains to how critical realist causal power can flexibly nuance the relations between cause (interrelations) and effect or, put differently, emergence. In social interpretive research, it follows therefore that beyond the judgmental objectivism in interpretive data, even the most replicable kind of automated analysis will give outcomes that intra-act with the researcher to let subjective understanding emerge that is probably unique (or endlessly complex) despite meticulous conceptual delimitation of the substantive domain.

\subsection{Social Archaeology, Time, and Spatial Analysis}

\subsubsection{The Inhabitant's Perspective}

It would appear that time is the dominant force that stands between archaeology and any aspirations of contributing to or operating as a social science. The obvious remark to make is that archaeology's subjects tend to be dead and those of social science are alive and kicking. However, the growing discourse on materiality and the influential popularity of ANT suggests the social sciences are struggling to reconcile their traditionally live human purview with the nonhuman elements of the world. As I have made explicit, there is not only a substantive but a meaningful (for research purposes) difference between human agency and nonhuman agency and whether an assemblage includes human agency. Giving material an active voice, thanks 
to its interrelations with human beings as conceived in the material, sustains an interhuman (i.e. social) mode of understanding of nonhuman things. That is, without any actual human agency currently being interrelated with nonhuman agency, we can project an understanding of the causal power (or intra-action) that emerges from a situation in which human agency would be present. While this mode of research may lose the a priori explanatory detail of sociocultural context or personal affect and biography_as available to social science in live situations-it supports an analytical intersubjective social understanding. ${ }^{11}$ Importantly, if social interpretive science of the material can be conducted without the live participation of human agency, there is in essence no difference between situations in the past and the present.

Within this chapter, I called upon the human scale and the perspective of human experience several times. As both the performativity in Barad's (2003) agential realism and causation in critical realism suggest, the presence of the material depends on the interrelation of human agency through participation. For the fiat understanding of material boundaries as a category of evidence this means that the active disposition of people in the built environment must be assumed. Or, put differently, the built environment must be actively inhabited for material boundaries to exist. For the purposes of social interpretation, we should therefore adopt an inhabitant's perspective (also Vis 2016) on understanding the material nature of boundaries. From this perspective we can then proceed to differentiate the diversity of the physical situation and construction of boundaries based on understanding how this influences their role in

\footnotetext{
${ }^{11}$ Agency in archaeology is very often concerned with the individual as a particular individual. In social science, insights gained can sometimes be evaluated against an individualised context of live participants. What this appeals to is Schumpeter's and Weber's classical idea of methodological individualism, where individual actions and motivations must explain social phenomena (Heath 2015), but accepting that the individual is a generalised analytical unit.
}

determining spatial frames and relations in human and social assemblages.

The inhabitant's perspective stands in contrast to the 'god's view' (Morton et al. 2014) or the god trick (Aitken and Craine 2006; Wood 1992; Monmonier 1996) of mapping from an impossibly high or distanced viewpoint and visualising and analysing data from a totalising perspective. Maps excel at giving data overviews and I do not argue against this. What I propose is that we should 'people the past' (or any material evidence) using a variety of dynamic spatial methods (see Morton et al. 2014) and create static data renderings which allow us ways towards understanding spatial situations from an inhabitant's perspective. It is not an argument for exact replication of experience, as indeed, in contemporary lives, we can never attain a complete replication of even our direct neighbour's perspective. Understanding the other and their time-space specific and social position and situation is inevitably always based on part projected fabrication; such is the artificiality of analysis.

One of the principal artificialities is the stasis of mapped information (even in most agentbased dynamic models, this is retained). Even if stasis nullifies the constant change and mutability as indicated by archaeological progressive time (see Meirion Jones 2015), it is actually quite consistent with inhabitants of spatial situations, such as built environments. We know the built environment can change and we are likely to have experienced such change, but in everyday life we do not expect it to. If sudden large changes occur, they are almost always disruptive (e.g. natural and human disasters, such as London 1666 , and major urban renewal programmes). In general, though, we expect spatial-material situations to last, both those transformed or constructed and those naturally occurring. By and large we expect materials to be stable (see Hodder 2014): our homes and things are still there after we return from work. The fact material spaces only appear stable on the surface is actually the most pragmatic attitude in daily life.

The consequence of assuming material stability means that, in the sense of mapping material boundaries, the stasis of the dataset will assume 
the interrelations that constitute their causal power are actively operated. Therefore, the built environment map is now static and dynamic at the same time. The active operation of interrelations generating causal power also intrinsically carries the ability for spatial situations to change. The subtle differences in how the intra-action takes place depend on each individual case, including personal and timespace-specific dependencies [sensu the time geographical adaptation of individual biography (Schütz 1967) into life-path by Pred (1981, 1984; see Vis 2009; cf. Hodder 2014)]. In the practice of operating material boundaries, which comes down to executing interrelationships and assemblages, their material status is reconfirmed. Intra-acting the built environment maintains it. The practice of 'mending wall' (see Oles 2015) consists of the repetition of closely similar intra-actions, stabilising the physical conditions on which the material nature relies. These conditions are the foundation of change over time ceteris paribus, excluding the effects of ongoing nonhuman processes (cf. site formation processes or Hodder's TT). This means that when material boundaries are not operated, for a period, the potential of generating a phenomenon of similar essential spatial characteristics remains. What we can map, then, is this potential, knowing that the phenomena would exist in varying rhythms.

\subsubsection{Synchronicity}

Throughout I have made passing remarks related to time such as in the built environment situation that is created through conjecture (cf. reconstruction). It has just become apparent that a stable rendering of the performativity of material boundary operations generates an artificial simultaneity in our data. The foregrounds a juxtaposition of synchronicity and diachronicity that is often found in archaeology and the interests of archaeological recording and analysis. Archaeology's proclivity to emphasise time as a developmental process often results in research foci that concentrate on diachronicity.
However, the static condition of spatial data or the stasis created by maps produces situations of simultaneous totalities. Consequently spatial data and spatial analysis are criticised, because they assume a synchronicity that sits uneasily with time as developmental process.

Galinié et al. (2004), Lefebvre (2009), and Rodier et al. (2009) have developed an archaeologically and historically dynamic model of information on urban fabric as an alternative to the more pervasive time-sliced (a particular or aggregate moment in time) representation, called OH_FET (based on 'historical objects'). Such approach relies heavily on the equal availability of archaeological and historical dating evidence across areas of space. In practice it is not only unusual to have equivalent dating evidence for all archaeological evidence of an area of built environment, but it is also difficult to account for the states, conditions, and iterations of persisting elements within the built environment. This is especially true when modelling 'historical objects' based on combinations of social use, space, and time (Rodier et al. 2009; Lefebvre 2009). Spatial analysis assumes the input dataset is synchronous. In contrast, analysing dynamically modelled spatial data runs the risk of 'fetishising' the formation processes of archaeological evidence instead of (social) developmental processes. However, the difficulty of incorporating temporal dynamics into spatial built environment data should not be an excuse for uncritical use of a synchronous mode of analysis.

Time-slice synchronicity should result from the judgmentally objective (sensu Galison 1998) representation of assembled spatiotemporal data. That data should then be converted into interpretive data through the stages informed by the concepts this chapter has introduced so far. The developmental significance in the inhabitant's perspective likely operates on a scale that differs from archaeological formation. Another sequence of concepts should be devised to identify the appropriate human scale(s) of time and how it manifests interrelations with archaeological evidence. Currently, for social interpretation, there are better 
concepts available for the critical understanding of synchronous analysis. This may therefore be preferable to introducing a further problem of data availability and the theoretical complications of data modelling, of course, depending on purpose and case. Time-slice synchronicity has the added advantage that it puts past built environment situations on a level playing field with analysing contemporary built environment situations.

Data that is not there cannot be analysed. The synchronicity assumed in analysing spatial datasets has the side-effect that the coincidence of all data entries makes implicit that the analysis will also assume that this coincidence is all that exists. A record of fragments thus is complete as a record in itself. Inhabitants of a past situation would not have encountered a fragmented world, and therefore I have introduced the preparatory step of conjecture. Conjecturing ensures the spatial information best approximates the social empirical reality of a past situation. The known unknown of any spatially determinant characteristics for which we do not have archaeological traces remains unresolved (the absence of evidence is not evidence of absence). Conjecture merely helps to avoid an analysis of fragments instead of past situations, even if our rendering of that situation is incomplete. Although Lucas (2015) stresses that the evidentiary fragment lacks a temporal dimension, when putting together (incl. conjecture) a time-slice of spatial data, we may pick any moment in the material presence of archaeological evidence that survives from a past situation. The incompleteness of evidence for a past situation does not rob the fragment of its duration. Complementing fragments with synchronic conjectures simply implies an analysis and interpretation focused on what archaeological evidence is evidence of.

Ultimately, these arguments improve our critical understanding of spatial analysis, but spatial analysis itself remains temporally undiscriminating. What is being analysed comprises a 'wouldbe' moment and situation of a (past) inhabited built environment, seeing all material boundaries as if operated at once.

\subsubsection{What Is Social Interpretation of Material Boundaries?}

There is nothing new about having to negotiate these limitations. However, to arrive at an 'interpretive GIS' and applying associate analytical tools, we must fully understand the extent of the opportunity for social interpretation. Many of the problems discussed so far tend to disappear into the background of 'archaeological evidencing'. It can be appreciated just how much influence the treatment of archaeological evidence has on exactly which kind of interpretive and analytical work is supported by it. At this stage we can ask, so why does it matter that our data best approximates a would-be inhabited built environment? What is its value, its contribution, its relevance? From the outset I placed the arguments in this chapter in the context of social interpretation, but until now virtually all effort has gone into preparing and seeing built environment data as material boundaries. What is the social interpretation of material boundaries?

With social interpretation of material evidence, I seek to place the material as a fundamental part of social science. This is not an attempt to reformulate the many guises of social archaeology (see Preucel and Meskell 2007) under a new heading. It should be seen as part of recent calls for archaeology to act as a social science and to contribute to pertinent societal issues (Smith et al. 2012; Kintigh et al. 2014; Smith 2015). In archaeology as a social science, it could be said that "we are no longer concerned with how these materials can be interpreted; instead we are interested in how these materials intra-acted with past people' (Meirion Jones 2015: 336), specifying our interpretive process and purpose. From this vantage point, the difference between the purviews of archaeology and social science is all but gone. The synchronous mode of analysis of spatially determinant characteristics further emphasises these equal terms of operation.

The primary cornerstones of our endeavour consist of spatial and human information. Therefore, here, social interpretation should contribute to understanding how human-environmental 
relations create built environment situations of being in the world, how these situations function, and how they develop (cf. Graham 1999 on refocusing research concerning Maya urbanness). Social interpretation provides a performative lens on socio-spatial practice as interrelated with the material environment to analyse and study constitutive society-space relations comparatively and historically (cf. Griffiths 2013). This kind of social interpretation is of undisputable value to social scientific questions on emergence and humanenvironmental relations, because it places the human past as an inextricable part of the continuing processes that determine the fundamental nature of human societies (cf. Kintigh et al. 2014). In doing so, archaeology can contribute to building an evidence base of scenarios containing the widest possible sociocultural form variety and environmentally situated developmental trajectories (sensu Smith 2012). Such evidence base will further enlighten the essential relations determining the nature of human inhabitation of the world. The social empirical reality of this is necessarily spatial.

This brings us to the conclusion that social interpretation of the spatially determinant characteristics of material boundaries composing built environments will revolve around the sociospatial opportunities involving humans introducing material presence and encountering material presence. The typical limitation to generally available archaeological physical information on space implies a focus on structure. So, after all, it is still about geometry, topology, morphology, and topography of built space, but exclusively through a socially constitutive lens on a human scale. Spatially determinant physical information is what Marcus (2017) would call a background (or context). The foreground being rather what is traditionally considered (landscape) architecture. In these terms, the structural elements of the background may depend on the architectonic constructions (perceptible results of building actions) of the foreground.

Space has a tendency of slipping into the background, ending up as something we think and act 'with' rather than think and act 'on' (Marcus 2017). However, archaeology's and architecture's developmental viewpoint clarifies immediately that the built environment is something that is made. Only acting on the naturally occurring physical environment (human-environmental intra-action) can create built environments, which consist of occupiable spaces constituted by things (boundaries) that specifically serve the purpose of inhabitation. To understand the essential nature of the background in terms of itself (see Marcus 2017), we must foreground the physical determinacy of the background (acting on and occupation). Consequentially, the research becomes about how space does what it does as relevant to the human perception and experience of their purpose to inhabit the world. The diversity (or differentiation) of material boundaries results from identifying the smallest intrinsically coherent elements (or operations) in which we construct and encounter spatially determinant characteristics (see Vis 2014b for an applied example).

Boundaries have been used pervasively as a heuristic reference. This conceptual example should not be confused with asserting that material boundaries have now become a prerequisite for spatial analysis in support of social interpretation. Nonetheless, the basic properties of boundaries grant spatial structure a relational plurality that classification according to discrete spaces does not. What is left is to place material boundaries in an analytically able toolkit to advance complex understanding of the situations in which they occur.

\subsection{Towards Interpretive GIS: A Prospect}

\subsubsection{The Challenge of Interpretive GIS}

It is only following this elaborate philosophical and theoretical preamble that we can confidently turn to GIS as a toolkit in aid of social interpretations of spatial data (here: built environments). Verhagen (2018, this volume) glances over 30 years of GIS applications in archaeology and emphasises the apprehension with which the more theoretically and interpretively inclined archaeologists have received 
it. The lack of direct theoretical engagement with GIS is still lamented during many CAA conferences (Computer Applications and Quantitative Methods in Archaeology). The outlook of this chapter is not for the archaeological 'spatial turn' to generate theory, but to generate theory for the 'spatial turn'. Though archaeological evidence is necessarily spatial, we should not allow spatial empiricism to become the driver of social insights. In this light it might be a fallacy to desire the integration of native GIS concepts in archaeological theory and interpretation. Yes, GIS could (and probably should) be part of a mixed multimethod approach, but when we dedicate ourselves to direct theoretical engagement with the spatial data GIS relies on, it becomes apparent we have to reconceptualise our data in GIS. Since we now have a concept of interpretive data, we should devise ways to appropriate GIS formats to become commensurable with the understanding packed into these data.

This strategy towards GIS is not an instant proponent of an eclectic use of spatial analytical tools (Hactgüzeller 2012; Hacıü̈zeller and Thaler 2014; but also in qualitative GIS: Cope and Elwood 2009). Constructive and defensible eclecticism requires a solid, that is, coherent and consistent, fundamental framework of the research process and knowledge production in which it is placed. How else can we evaluate the contribution and validity of its results? However, as material boundaries are but one aspect or operation in the constitution of built environments and used here to contribute to just one mode of understanding, this strategy does support pluralism in perspectives. What this strategy requires first, before even considering mixing and matching methods and ideas, is to work through the consequences of reconciling GIS as a toolkit with interpreting archaeological evidence. That is because the implications of following a fundamental theoretical route into GIS [as propagated by Wheatley and Gillings (2000), Gillings (2012), Hacıüzzeller (2012), McEwan and Millican (2012), Kosiba and Bauer (2013), Wheatley (2014); and following the lead of critique developed in Geographical Information Science by Kwan and Schwanen
(2009), Leszczynski (2009)] are much more profound.

As I have shown, it suggests that the very structure of empirically recorded and representational spatial data needs to be questioned on top of the properties of the technology and its tools, in order to avoid the 'black box effect' (Griffiths 2013). Carrying out the critical questioning that archaeological evidence is subjected to in this chapter strongly suggests that the structure (visual forms of empirical representation) in which spatial data reaches us is often suboptimal and sometimes even inappropriate for specific end user purposes. The data structure is suboptimal because data production was the work of a different ontological register, and the structure may be inappropriate because its format explicitly permits the use of measures and tools that were produced in a different ontological register.

\subsubsection{Towards Interpretive Data Structures}

As noted before, Nicholas and Markey (2015) point out that archaeological interpretation has relied heavily on analogous information, even in contextual archaeology (see Hodder and Hutson 2003). In the empirical practice of producing representative maps resulting from archaeological surveying and excavation, a level of interpretation is applied that identifies the (sociocultural) categories of the features we think we have seen (cf. Hutson 2015). Such identifications are typically the outcome of a form of reasoning that goes something like this: 'this' must have been 'that', where 'this' is one or multiple archaeological traces and 'that' is a choice of preconceived categories or entities derived from other (comparable) information. If an archaeological map consists of representation as a cartographic reflection of reality (cf. Hactgüzeller 2012), then we must ask: whose (or which) reality? Whatever the categories of interpretation are derived from arguably makes up the reality the map imparts from that moment. Even though the map contains 
physical information shaped in space, the categories identified may not have been defined on the basis of such information at all. How we regard our evidence-even saying it 'is archaeological'-will determine to a large extent what we consider to be real (see Lucas 2012; Meirion Jones 2015).

Contrary to Lucas' (2012) recommendation to nuance the linearity from data collection to interpretation, the conceptual and preparatory processes of this chapter assume such linearity. That is not because data collection and interpretation could not be constructively blended (provided one continues working within one ontological register), but because end users of data will always depend on acquiring data prepared through different research. As recognised before, the requirements of future analyses cannot be foreseen, making data collection and recording for future use an especially tricky balance to strike. Lucas' (2012) solution of employing the concept of materialisation conveying the process of becoming of archaeological entities is unlikely to solve that problem. Critical realism teaches us that entities emerge through interrelations, but the interrelations of site formation and interpretive recording that make up Lucas' archaeological entities are not the entities archaeology as social science pursues an understanding of. When analysing interpretive data to advance social interpretations, we are no longer concerned with the mode of interpretation that asks what archaeological evidence is evidence of (cf. Lucas 2012, 2015; Meirion Jones 2015). With interpretive data we construct a spatial world of material evidence: a world of material presence. ${ }^{12}$ This is a view from beyond

\footnotetext{
${ }^{12}$ It could be argued that the idea of a 'world of presence' is an example of nonrepresentational use of GIS (see Hacıüzeller 2012). A world of presence is necessarily the complete evidence of particular occurrences or phenomena, but one should be vigilant not to mistake that to mean all evidence or representing the whole of reality. In the colloquial sense, within GIS this is still visually (re) presented. We cannot overcome ourselves as researchers to become inhabitants of the spatial situation constructed in data. This resembles the paradoxical conundrum created by the impasse of situatedness resulting from deeply
}

any disciplinary evidence. Instead, it conjures up a live world of would-be human participants in intra-actions.

The next concern is establishing the data structure (format, elements, units, and their relations) of such a world of presence. The term geographical information system indicates that as long as phenomena are geographically located (which in a strict sense applies to all archaeology) it can store information on them. It is up to us to decide how we store information with a geospatial reference. The task at hand has been defined as pursuing understandings of the spatially determinant characteristics of occupiable spatial entities constituted from the smallest intrinsically coherent elements (or operations) as constructed and encountered by people. With this, the range of possible entities to emerge can be varied, and they have not been named yet. Any concurrence with entities presented as spatial data derived from other research would be a coincidence. For example, when working towards boundaries of spaces, it is unlikely we will find 'houses' in our finished dataset. Even though the category of a house could be an example of interpretive data, material boundary interrelations will disaggregate a house into distinct boundary parts. If working towards the occupational function of spaces, this may be quite the reverse.

The prominent critical realist research process of iterative abstraction (Sayer 1981; Yeung 1997) suggests that to get to the actual identifiable structure of interpretive data a sequence of contrasting 'material evidence concepts' to physical evidence (empirical edges of spatial discontinuity) follows, until they reach stability as empirically applicable material boundary concepts. Once these material boundary concepts are applied, we have interpretive data which are structured in an appropriate way, commensurable to the performative theory that informs the socio-

acculturated emic research or indeed 'archaeological phenomenology'. 
spatial significance of boundaries. For the development of boundary line type (BLT) mapping (Vis, under review, 2014b), I have gone through this process using radically contrasting spatial urban built environment datasets. It resulted in mappable concepts that to date appear stable and a data structure that posed genuine challenge to the traditional abilities of GIS software. The concepts proved entirely possible to map, albeit a laborious and complex process. However, GIS proved natively virtually incapable to query the data structure representing the concepts sensibly and commensurably without further original tool development.

The data structure that was generated by simply applying the concepts was not premeditated. In summary, this resulted from the spatial differences between material boundary operations (i.e. those enclosing several distinct occupiable spaces at once, those circumscribing one occupiable space discretely, and those specifying a characteristic persisting for only part of a circumscription of a discrete occupiable space), and the necessarily particular relations of each occupiable space to its outside (consisting of other bounded occupiable spaces). It turned out that data identification according to elementary boundary operations as experienced from the human perspective of one side of the boundary and then the other, initially produces further disaggregation into units. These units then constitute each and every occupiable space. Once mapped, this material boundary data is at once fully quantifiable (and geospatial) and contains an interpretively rich yet critically delimited description.

\subsubsection{The Interpretive Advantages of GIS}

Verhagen (2018, this volume) displays a perceptive awareness of the advantages of using GIS, many aspects of which are indeed advantages in the context of pursuing social interpretation. I will therefore only expand on a few, starting with the statement that GIS as a heuristic toolkit is not as reductionist as it appears. In fact, GIS is software and software is code. If we see a computer as a capsule (the hardware) with a capacity of artificial intelligence, it is very apparent that nothing is fixed. In principle GIS provides one with a complete expanse of adaptability to requirements. Naturally, to effectuate changes or develop tools within GIS software, the ability to code is an indispensable skill. The real challenge, it would appear, is to identify exactly what one's requirements are and to ground them in theory from start to finish. This is only possible through a fundamental process of critically questioning the quality and information behind any spatial evidence and meticulously defining the (interpretive or analytical) purpose of the research. Only then can interpretive data structures be created in empirical applications.

The term 'interpretive GIS' is used deliberately. This marks its distinction from the social interpretation-ridden qualitative GIS (qualGIS) and critical GIS, which are more established fields with slightly diverging remits and connotations (O'Sullivan 2006; Elwood and Cope 2009; Hactgüzeller 2012). However, the particular theoretical-archaeological challenge I subject GIS to is not without overlap. Mixed and multimethod approaches may already qualify as qualitative GIS, and certainly this field includes the geolocation of qualitative ideas or data by adding them into GIS environments (Kwan and Knigge 2006; see examples in Cope and Elwood 2009). In fact, taking most GIS software's native abilities, the problem is not that GIS data cannot be invested with qualitative meaning at all. The attributes in the database structure allow one to attach all kinds of meaning and interpretation to any bit of spatial data. Images (usually seen as qualitative data) are raster format and can simply be imported into a GIS environment. In addition, insofar as qualitative GIS embraces the uses of GIS in qualitative research, various archaeological applications of GIS could be grouped under this umbrella without doubt. And so could historical GIS (HGIS) (see Gregory and Ell 2007). The 
relevance of critical GIS to archaeology is elaborately reviewed by Hacigüzeller (2012). Classifying the research process this chapter sets out as part of an existing field is arguably a moot point in comparison to its pertinent progress. Therefore, the term 'interpretive GIS', following on from interpretive data, captures the purpose it serves well.

At the least I will claim that the approach I promote is a theory-laden and developmental approach to GIS that forces GIS research to operate on a higher critical plane than normally is brought to the fore, even if not exactly as Hacıüzeller (2012) or Verhagen (2018, this volume) proposes. When following this path, it may indeed prove necessary to devise software interventions. In qualitative GIS the software development of GIS to imbue or directly import qualitative data and associated analytical techniques is also recognised as a notable advance (Elwood and Cope 2009; Jung 2009). It is on the basis of the structure of interpretive data that it will become apparent that new GIS abilities or tools may need to be developed. Such tools must be capable of working in respect of the new data structure in order to ask the interpretive questions this structure warrants (see Vis, under review). Innovative and purposive tool development enables spatial archaeologists to grow independent from the toolsets and research environments developed by experts external to our discipline (see Verhagen 2018, this volume). Furthermore, when theoretical understanding structures the spatial data that is queried, the interpretive value and appropriateness of the quantitative tools analysing that structure can be much better evaluated. We can ask how the tools and their measures are capable of revealing or supporting us in identifying explanatory causal powers within our dataset (cf. Smith 2015).

The conceptual implications of identifying material boundaries as spatial data have demonstrated that when it is not necessary to alter GIS software, still new theoretically informed data structures can be developed. But boundaries as a concept offer just one of undoubtedly many powerful ways in which we can reimagine and rearrange our data according to interpretive spatial requirements, ${ }^{13}$ yet to be fully explored. Listing the rudimentary carriers of information in GIS, at face value, they may appear as a list of limitations (i.e. raster, an invariable pixel size with assigned values; vector, a combination of points, polylines, and polygons; a geodatabase supporting and attributing information to each spatial element). Instead, in terms of topography, spatial morphology, topology, and spatial relations, there is a truly vast array of possibilities to structure data before software manipulation. Many data structures will have been used in previous and current research; many structures may only exist hypothetically and have yet to find a use. This is where interpretive GIS can benefit and advance the field. GIS not only enables pluralism (Verhagen 2018, this volume), but GIS also enables experimentalism and exploration. Since it is up to the researcher which data is stored and projected in a GIS and how it appears, the sky is literally the limit.

At the low-tech level, the great advantage of digital spatial data over a printed-out map with a legend is the manipulability and comparability of mapped data. Adjusting simply how the elements on the map appear (symbology and classification) or layering several maps (an HGIS favourite), in either vector or raster format, can provide huge leaps in driving interpretive questions and spatially grounding our understanding. Following the arguments for affective geovisualisation (Aitken and Craine 2006, 2009), the traditional investigative capacities of GIS can be placed in an interpretive or qualitative research framework. When the aim is not to elicit an emotional response or understanding from the geovisualisation itself (cf. Aitken and Craine 2006), one could still conceptually map geo-affective information for visual inspection

\footnotetext{
${ }^{13}$ Network science, while often not geographical or even spatial, should be listed among the ways in which notable advancements in knowledge production have been achieved using new data structures and associated queries and measures [see Brughmans et al. (2016)].
} 
or further analysis instead of geo-representations. Viewing GIS this way brings research back to maps as causal power and images, and there are many examples in the history of science of why visual exploration is a valuable resource.

Finally, when working with spatial data, our options are not restricted to GIS alone. Some graphics and design, graph, and social network analysis software may offer alternative pathways into launching spatial investigations. The advantage of GIS is that this can be done while projected onto geographical space, which is not always necessary, but in terms of underpinning comparability and the complex linking of information is very powerful.

\subsubsection{Concluding Reflection}

What has been demonstrated here is the culmination of a hard-fought battle to forge the alignment of the scientific empiricism and social scientific conceptualism of archaeology (regarded as social scientific conduct). It strongly suggests there is no easy way to develop interpretive GIS. Yet, for the sake of archaeological argumentation and relevance, I believe it is worthwhile. Especially for those ready to criticise GIS or computational archaeology as unwarranted reductionism and devoid of theoretical meaning, the simple but rudimentary question "what is archaeological spatial data exactly and what can we do with it to make it serve social interpretation?' opens developmental paths of high potential. These paths may include entirely new discovery, previously impossible queries or exploration, juxtaposing and layering plural concepts and methods, or simply advancing the evidence base of current hypotheses. It truly is an open invitation for rigorous theorists to apply themselves to work through the implications of geospatially anchored ideas as necessarily related to their empirical archaeological counterparts. The outcomes and consequences will form an opportunity to shape both GIS formats and analytical research creatively.

\section{References}

Abbott A (1995) Things of boundaries. Soc Res 62 (4):857-882

Aitken S, Craine J (2006) Guest editorial: Affective geovisualizations. Directions Magazine. http://www. directionsmag.com/entry/guest-editorial-affectivegeovisualizations/123211. Accessed 05 July 2016

Aitken S, Craine J (2009) Into the image and beyond: affective visual geographies and GIScience. In: Cope M, Elwood S (eds) Qualitative GIS: a mixed methods approach. Sage, Los Angeles, pp 139-155

Arnoldi J (2001) Niklas Luhmann: an introduction. Theory Culture Soc 18(1):1-13

Barad K (2003) Posthumanist Performativity: towards an understanding of how matter comes to matter. Signs J Women Cult Soc 28(3):801-832

Bintliff J, Pearce M (2011) Introduction. In: Bintliff J, Pearce M (eds) The death of archaeological theory? Oxbow Books, Oxford, pp 1-6

Brughmans T, Collar A, Cowards F (eds) (2016) The connected past: challenges to network studies in archaeology and history. University of Oxford Press, Oxford

Cope M, Elwood S (eds) (2009) Qualitative GIS: a mixed methods approach. Sage, Los Angeles

Cox KR (2013) The continuing relevance of old debates. Dialogues Hum Geogr 3(1):49-55

Demarest AA (1997) The Vanderbilt Petexbatun Regional Archaeological Project 1989- 1994: overview, history, and major results of a multidisciplinary study of the Classic Maya collapse. Anc Mesoam 8:209-227

Ellen R (2010) Theories in anthropology and anthropological theory. J Roy Anthropol Inst 16:387-404

Elwood S, Cope M (2009) Introduction: qualitative GIS: forging mixed methods through representations, analytical innovations, and conceptual engagements working from a theoretical perspective. In: Cope M, Elwood S (eds) Qualitative GIS: a mixed methods approach. Sage, Los Angeles, pp 1-12

Fahlander F (2012) Are we there yet?: archaeology and the postmodern in the new millennium. Curr Swed Archaeol 20:109-129

Fletcher RJ (2004) Materiality, space, time and outcome. In: Bintliff JL (ed) A companion to archaeology. Blackwell, Oxford, pp 110-140

Galinié H, Rodier X, Saligny L (2004) Entités fonctionnelles, entités spatiales et dynamique urbaine dans la longue durée. Hist Mes 19(3/4):223-242

Galison P (1998) Judgment against objectivity. In: Jones CA, Galison P (eds) Picturing science producing art. Routledge, New York, pp 327-359

Galison P (2000) Objectivity is romantic. In: Frye BE (ed) The humanities and the sciences. American Council of Learned Societies Occasional Paper 47:15-43. http://archives.acls.org/op/op47-3.htm. Accessed 09 July 2016 
Galison P (2010) The objective image. Faculteit Geesteswetenschappen, Universiteit Utrech, Utrecht

Gillings M (2012) Landscape phenomenology, GIS and the role of affordance. J Archaeol Method Theory 19 (4):601-611

Graham E (1999) Stone cities, green cities. Archeol Pap Am Anthropol Assoc 9(1):185-194

Gregory IN, Ell PS (2007) Historical GIS: technologies, methodologies and scholarship. Cambridge University Press, Cambridge

Griffiths S (2013) GIS and research into historical 'spaces of practice': overcoming the epistemological barriers. In: von Lünen A, Travis C (eds) History and GIS: epistemologies, considerations and reflections. Springer, Dordrecht, pp 153-171

Hacıüzeller P (2012) GIS, critique, representation and beyond. J Soc Archaeol 12(2):245-263

Hactgüzeller P, Thaler U (2014) Three tales of two cities? A comparative analysis of topological, visual and metric properties of archaeological space in Malia and Pylos. In: Paliou E, Lieberwirth U, Polla S (eds) Spatial analysis and social spaces: interdisciplinary approaches to the interpretation of prehistoric and historic built environments. TOPOI 18, Berlin Studies of the Ancient Worlds. De Gruyter, Berlin, pp 203-262

Hall ET (1996) Foreword. In: Pellow D (ed) Setting boundaries: the anthropology of spatial and social organization. Bergin \& Garvey, Westport, pp vii-viii

Heath J (2015) Methodological individualism. In: Zalta EN (ed) The stanford encyclopedia of philosophy (Spring 2015 Edition). http://plato.stanford.edu/ archives/spr2015/entries/methodological-individual ism/. Accessed 07 July 2015

Hodder I (2014) The entanglements of humans and things: a long-term view. New Literary Hist 45(1):19-36

Hodder I, Hutson SR (2003) Reading the past: current approaches to interpretation in archaeology. Cambridge University Press, Cambridge

Hutson SR (2012) Unavoidable imperfections: historical contexts for representing ruined Maya buildings. In: Pillsbury J (ed) Past presented: archaeological illustration and the ancient Americas. Dumbarton Oaks, Washington, pp 283-316

Hutson SR (2015) Adapting LiDAR data for regional variation in the tropics: a case study from the Northern Maya Lowlands. J Archaeol Sci Rep 4:252-263

Ingold $\mathrm{T}$ (2008) Bindings against boundaries: entanglements of life in an open world. Environ Plann A 40(8):1796-1810

Jones R (2009) Categories, borders and boundaries. Prog Hum Geogr 33(2):174-189

Jones R (2010) The spatiality of boundaries. Prog Hum Geogr 34(2):263-267

Jung JK (2009) Computer-aided qualitative GIS: a software-level integration of qualitative research and GIS. In: Cope M, Elwood S (eds) Qualitative GIS: a mixed methods approach. Sage, Los Angeles, pp 115-136
Kintigh KW, Altschul J, Beaudry M, Drennan R, Kinzig A, Kohler T, Limp WF, Maschner $\mathrm{H}$, Michener W, Pauketat T, Peregrine P, Sabloff J, Wilkinson T, Wright H, Zeder M (2014) Grand challenges for archaeology. Am Antiq 79(1):5-24

Kleinman A (2012) Intra-actions. Mousse 34:76-81

Koch A (2005) Autopoietic spatial systems: the significance of actor network theory and systems theory for the development of a system theoretical approach of space. Soc Geogr 1(1):5-14

Kosiba S, Bauer AM (2013) Mapping the political landscape: towards a GIS analysis of environmental and social difference. J Archaeol Method Theory 20 (1):61-101

Kwan MP, Knigge L (2006) Doing qualitative research with GIS: an oxymoronic endeavor? Environ Plann A 38(11):1999-2002

Kwan MP, Schwanen T (2009) Critical quantitative geographies. Environ Plann A 41:261-264

Lefebvre B (2009) How to describe and show dynamics of urban fabric: cartography and chronometry? In: Proceedings of the 37th computer applications and quantitative methods in archaeology conference, Williamsburg. http://www.caa2009.org/articles/ Lefebvre_Contribution224_a.pdf. Accessed 26 Sept 2013

Leszczynski A (2009) Quantitative limits to qualitative engagements: GIS, its critics, and the philosophical divide. Prof Geogr 63(3):350-365

Lilley KD (2011) Urban mappings: visualizing late medieval Chester in cartographic and textual form. In: Clarke C (ed) Mapping the medieval city. University of Wales Press, Cardiff, pp 19-41

Lucas G (2012) Understanding the archaeological record. Cambridge University Press, New York

Lucas G (2015) Evidence of what? On the possibilities of archaeological interpretation. In: Chapman R, Wylie A (eds) Material evidence: learning from archaeological practice. Routledge, Abingdon, pp 311-323

Luhmann N (1986) The autopoiesis of social systems. In: Geyer F, van der Zouwen J (eds) Sociocybernetic paradoxes: observation, control and evolution of selfsteering systems. Sage, London, pp 172-192

MacEachren AM (2004) How maps work: representation, visualization and design. The Guilford Press, New York

Marcus L (2017, in prep) Spatial capital: measures and meanings (unpublished manuscript)

McEwan DG, Millican K (2012) In search of the middle ground: quantitative spatial techniques and experiential theory in archaeology. J Archaeol Method Theory 19(4):491-494

Meirion Jones A (2015) Meeting the past halfway: a consideration of the ontology of material evidence in archaeology. In: Chapman R, Wylie A (eds) Material evidence: learning from archaeological practice. Routledge, Abingdon, pp 324-338

Monmonier M (1996) How to lie with maps. University of Chicago Press, Chicago 
Morton SG, Peuramaki-Brown MM, Dawson PC, Seibert JD (2014) Peopling the past: interpreting models for pedestrian movement in ancient civic-ceremonial centres. In: Rau S, Schönherr E (eds) Mapping spatial relations, their perceptions and dynamics: the city today and in the past. Springer International, Heidelberg, pp 25-44

Nicholas G, Markey N (2015) Traditional knowledge, archaeological evidence, and other ways of knowing. In: Chapman R, Wylie A (eds) Material evidence: learning from archaeological practice. Routledge, Abingdon, pp 287-307

O’Sullivan D (2006) Geographical information science: critical GIS. Prog Hum Geogr 30(6):783-791

Oles T (2015) Walls: enclosure and ethics in the modern landscape. University of Chicago Press, Chicago

Oliver R (1993) Ordnance survey maps: a concise guide for historians. The Charles Close Society, London

Pellow D (ed) (1996) Setting boundaries: the anthropology of spatial and social organization. Bergin \& Garvey, Westport

Pratt AC (1995) Putting critical realism to work: the practical implications for geographical research. Prog Hum Geogr 19(1):61-74

Pred AR (1981) Social reproduction and the timegeography of everyday life. Geogr Ann B 63(1):5-22

Pred AR (1984) Place as historically contingent process: structuration and the time-geography of becoming places. Ann Assoc Am Geogr 74(2):279-297

Preucel RW, Meskell L (2007) Knowledges. In: Meskell L, Preucel RW (eds) A companion to social archaeology. Blackwell, Oxford, pp 3-22

Rodier X, Saligny L, Lefebvre B, Pouliot J (2009) ToToPI (Topographie de Tours Pré-Industriel): a GIS for understanding urban dynamics based on the OH_FET model (Social Use, Space and Time). In: Proceedings of the 37 th computer applications and quantitative methods in archaeology conference, Williamsburg. http:// proceedings.caaconference.org/files/2009/41_Rodier_ et_al_CAA2009.pdf. Accessed 08 July 2016

Sayer A (1981) Abstraction: a realist interpretation. Radic Philos 28:6-15

Sayer A (1993) Postmodernist thought in geography: a realist view. Antipode 25(4):320-344

Sayer A (2013) Looking forward to new realist debates. Dialogues Hum Geogr 3(1):22-25

Schütz A (1967) The phenomenology of the social world. Northwestern University Press, Evanston

Sherratt A (1993) The relativity of theory. In: Yoffee N, Sherratt A (eds) Archaeological theory: who sets the agenda. New directions in archaeology. Cambridge University Press, Cambridge, pp 119-130

Smith B (2001) Fiat objects. Topoi 20(2):131-148

Smith ME (2011) Empirical urban theory for archaeologists. J Archaeol Method Theory 18:167-192

Smith ME (2012) The role of ancient cities in research on contemporary urbanization. UGEC Viewpoints 8:15-19

Smith ME (2015) How can archaeologists make better arguments? SAA Archaeol Rec 15(4):18-23
Smith B, Varzi AC (1997) Fiat and bona fide boundaries: towards an ontology of spatially extended objects. In: Hirtle S, Frank AU (eds) Spatial information theory a theoretical basis for GIS. Springer, Berlin, pp 103-119

Smith B, Varzi AC (2000) Fiat and bona fide boundaries. Philos Phenomenol Res 60(2):401-420

Smith ME, Feinman GM, Drennan RD, Earle T, Morris I (2012) Archaeology as a social science. PNAS Early Edition, pp 1-5, doi:https://doi.org/10.1073/pnas. 1201714109

Verhagen P (2018) Spatial analysis in archaeology: moving into new territories. In: Siart C, Forbriger M, Bubenzer O (eds) Digital geoarchaeology: new techniques for interdisciplinary human-environmental research. Springer, Heidelberg, pp 11-26

Vis BN (2009) Built environments, constructed societies: inverting spatial analysis. Sidestone Press, Leiden

Vis BN (2012) The death of archaeological theory? (Book review). Antiquity 86:274-275

Vis BN (under review) Cities made of boundaries: mapping social life in urban form. UCL Press, London

Vis BN (2013) Establishing boundaries: a conceptualisation for the comparative social study of built environment configurations. Spaces Flows 2(4):15-29

Vis BN (2014a) Boundary concepts for studying the built environment: a framework of socio-spatial reasoning for identifying and operationalising comparative analytical units in GIS. In: Earl G (ed) Proceedings of CAA 2012 Southampton. Amsterdam University Press, pp 820-838. http://dare.uva.nl/aup/en/record/ 500958. Accessed 01 June 2016

Vis BN (2014b) Mapping socio-spatial relations in the urban built environment through time: describing the socio-spatial significance of inhabiting urban form. In: Rau S, Schönherr E (eds) Mapping spatial relations, their perceptions and dynamics: the city today and in the past. Lecture notes in geoinformation and cartography. Springer International, pp 45-93

Vis BN (2016) The material logic of urban space. J Space Syntax 6(2):271-274

Wallace S (2011) Contradictions of archaeological theory: engaging critical realism and archaeological theory. Routledge, Oxford

Webmoor T (2007) What about 'one more turn after the social' in archaeological reasoning?: taking things seriously. World Archaeol 39(4):563-578

Webmoor T, Witmore CL (2008) Things are us!: a commentary on human/things relations under the banner of a 'social' Archaeology. Nor Archaeol Rev 41 (1):53-70

Werlen B (2005) Regions and everyday regionalizations: from a space-centred towards an actioncentred human geography. In: van Houtum $\mathrm{H}$, Kramsch $\mathrm{O}$, Zierhofer $\mathrm{W}$ (eds) Bordering space. Ashgate, Aldershot, pp $47-60$

Wheatley D (2014) Connecting landscapes with built environments: visibility analysis, scale and the senses. In: Paliou E, Lieberwirth U, Polla S (eds) Spatial analysis and social spaces: interdisciplinary approaches to the interpretation of prehistoric and historic built 
environments. TOPOI 18, Berlin Studies of the Ancient Worlds. De Gruyter, Berlin, pp 115-134

Wheatley D, Gillings M (2000) Vision, perception and gis: some notes on the development of enriched approaches to the study of archaeological visibility. In: Lock $G$ (ed) Beyond the map: archaeology and spatial technologies. Nato science series A: life sciences. IOS Press, Amsterdam, pp 1-27
Wood D (1992) The power of maps. The Guilford Press, New York

Yeung HW (1997) Critical realism and realist research in human geography: a method or a philosophy in search of a method? Prog Hum Geogr 21(1):51-74

Zierhofer W (2002) Speech acts and space(s): language pragmatics and the discursive constitution of the social. Environ Plann A 34(8):1355-1372

Open Access This chapter is licensed under the terms of the Creative Commons Attribution 4.0 International License (http://creativecommons.org/licenses/by/4.0/), which permits use, sharing, adaptation, distribution and reproduction in any medium or format, as long as you give appropriate credit to the original author(s) and the source, provide a link to the Creative Commons license and indicate if changes were made.

The images or other third party material in this chapter are included in the chapter's Creative Commons license, unless indicated otherwise in a credit line to the material. If material is not included in the chapter's Creative Commons license and your intended use is not permitted by statutory regulation or exceeds the permitted use, you will need to obtain permission directly from the copyright holder. 